\title{
Anti-CD2 and anti-CD3 induced T cell cytotoxicity of human intraepithelial and lamina propria lymphocytes
}

\author{
J Rüthlein, G Heinze, I O Auer
}

\begin{abstract}
The effector function of immunocompetent cells in the gut mucosa has not yet been defined. The cytotoxic function of these cells might be important in the normal immune response and could be relevant to the mucosal damage seen in inflammatory conditions. The cytotoxic function of isolated intraepithelial and lamina propria mononuclear cells in six and 18 hour assays after the addition of various stimuli that interact with the human leukocyte antigens $C D 2$ and $C D 3$ on the mucosal effector cells was investigated. $T$ cell phenotypes were determined using CD4, CD8, and HML1 to characterise cells of the appropriate compartments. Anti-CD3 and phytohaemagluttinin can induce toxic activity of lamina propria lymphocytes in most individuals after six hours and in all individuals after 18 hours. Anti-CD2, antiCD3, and phytohaemagluttinin are similarly effective at triggering lamina propria lymphocytes. Intraepithelial lymphocytes contain predominantly CD8 and HML1 positive T cells, differentiating phenotypically intraepithelial lymphocytes from lamina propria lymphocytes. Intraepithelial lymphocytes are not cytotoxic at six hours, but have a toxic function comparable with lamina propria lymphocytes after 18 hours with all three triggers. Intraepithelial lymphocytes from inflamed mucosa (Crohn's disease and diverticulitis) mediate significantly reduced cytotoxicity in vitro compared with normal mucosa, whereas lamina propria lymphocyte toxicity is not different. Reduced numbers of cytotoxic cells and reduced reactivity to the trigger substances used after in vivo activation or cold target inhibition could explain the observed differences between intraepithelial lymphocytes from inflamed and uninflamed mucosa. Changes in cell mediated cytotoxicity of intraepithelial lymphocytes and lamina propria lymphocytes may be involved in the mucosal damage in these inflammatory conditions.

(Gut 1992; 33: 1626-1632)
\end{abstract}

Medizinische Universitätsklinik Würzburg, Germany J Rüthlein

G Heinze

Juliusspital, Würzburg, Germany I O Auer

Correspondence to: Dr J Rüthlein, Medizinische Universitätsklinik, JosefSchneider-Str 2, 8700 Würzburg, Germany.

Accepted for publication 19 May 1992 peripheral blood. ${ }^{12}$ There is considerable evidence that the immunocompetent cells distributed diffusely in the mucosal tissue are the effector limb of the immune system. Intraepithelial lymphocytes (IEL) and lamina propria lymphocytes (LPL) can be distinguished histologically and phenotypically. Effector functions such as proliferation, help in immunoglobulin production, lymphokine production, and suppressor function have all readily been shown in human LPL, but IEL proliferation and lymphokine production could be shown only under particular conditions that are not necessary for other T cells. ${ }^{3+}$ The cytotoxic function of human IEL and LPL has been difficult to study. "

Neither LPL nor IEL contain phenotypically CD16 + natural killer cells. LPL without further purification of subpopulations have marginal spontaneous cell mediated cytotoxic function (SCMC).$^{1+}$ However, unpurified isolated LPL can acquire cytotoxic function after culture with mitogens or interleukin $2 .^{1315}$ Intestinal mononuclear cells, which consist mainly of LPL, are also able to exert a cytotoxic function without prestimulation if mediators such as lectins, antibody, or epithelial cell associated components are used. ${ }^{16} 17$ These data support the idea that freshly isolated LPL have a cytotoxic function, but triggering of this function depends on unknown interactions.

A spontaneous cytotoxic function of IEL has been shown in several species, ${ }^{18}{ }^{19}$ and the "large granular lymphocyte' appearance of a considerable percentage of human IEL makes it likely that these also have cytotoxic function. ${ }^{1220} \mathrm{~A}$ spontaneous toxic function of human IEL against K562 cells, however, could not be shown by several investigators. Recently, Taūnk et al ${ }^{20}$ showed that jejunal IEL display spontaneous cytotoxicity with target cell restriction that differs from peripheral blood natural killer cells. But IEL are much more abundant in the human duodenum and jejunum than in normal ileum and colon, suggesting that these cells have a different functional activity. In our study we wanted to examine the toxic function of IEL and LPL from the colon and terminal ileum as these areas are commonly involved in neoplastic and inflammatory diseases with tissue damage.

Anti-CD3 is able to trigger cytotoxic $\mathrm{T}$ cell clones to become cytotoxic to bystander cells that are not HLA matched. ${ }^{21-23}$ This model was transposed to a mixed population of freshly isolated peripheral blood lymphocytes ${ }^{2426}$ and it was proposed that anti-CD3 induced cell mediated cytotoxicity is a function of in vivo generated cytotoxic $\mathrm{T}$ cells. CD3-induced cell mediated cytotoxicity offers a model in which these cells are triggered irrespective of their specificity and without conforming to HLA restriction. CD3induced cell mediated cytotoxicity of freshly isolated LPL was shown by Shanahan et $a l^{27}$ and Rüthlein et $a l^{28}$ without further purification steps, indicating that cytotoxic $T$ cells and not natural killer cells are the major cytotoxic effector cells in human mucosal tissue. 
It was shown by Meuer et $a l^{29}$ that $\mathrm{T}$ cells can be induced to proliferate through CD2. In contrast to peripheral blood cells, stimulation of LPL by anti-CD2 leads to a more vigorous proliferative response than that with antiCD3 ${ }^{3031}$ It has been suggested that $C D 2$ may be the most potent activation receptor in LPL. As stimulating anti-CD2 mabs can also induce cytotoxicity of cytolytic $T$ cell and natural killer cell clones $^{32}$ we have investigated whether anti-CD2 induced cell mediated cytotoxicity of freshly isolated IEL and LPL is more effective than CD3-induced cell mediated cytotoxicity. We also tested for phytohaemagluttinin-induced cell mediated cytotoxicity because this lectin binds to $\mathrm{T}$ cell receptor (TCR)-CD3 as well as to $\mathrm{CD} 2^{33-36}$ on the cell surface and may induce a more potent cytolytic effect by using both pathways

\section{Methods}

\section{STUDY POPULATION}

The intestinal specimens were obtained from patients undergoing surgical resection of the colon $(n=25)$ or ileum $(n=8)$ at the University of Würzburg or at the Juliusspital Würzburg. The study was approved by the ethical committee of the University of Würzburg. We studied 19 patients with colonic carcinoma (unaffected tissue was used), six patients with diverticulitis, three patients with ulcerative colitis, and five patients with Crohn's disease. In inflammatory bowel disease and diverticulitis patients we used inflamed mucosa.

\section{TARGET CELLS AND CULTURE MEDIA}

The target cell lines K562 and T84 colon tumour were obtained from American Type Culture Collection, Rockville, MD, USA. K562 cells were maintained at $37^{\circ} \mathrm{C}$ in a humidified atmosphere with $5 \% \mathrm{CO}_{2}$ in RPMI 1640 medium (Gibco, Berlin, Germany) supplemented with $10 \%$ fetal calf serum (Gibco), penicillin/streptomycin (Gibco), fungizone (amphotericin B) and $20 \mathrm{mM}$ Hepes. T84 were cultured in DMEM nutrient mix F12 medium (Gibco) with the same supplements and the same culture conditions.

\section{ANTIBODIES AND LECTINS}

Monoclonal anti-CD3 (OKT3) was used as 1:100 dilution of ascitic fluid of the hybridoma CRL8001, ATCC, Rockville. Three anti-CD2 monoclonal antibodies (clone 3T48B5, antiT11.2, and anti-T11.3) were used as a mixture with 1: 4000 dilutions of each antibody. All CD2 antibodies were obtained as ascitic fluid from $\mathrm{S}$ Meuer, Heidelberg, Germany. Anti-HML-1 antibody was purchased from Immunotech SA, Marseille, France. Anti-CD3-FITC (clone UCHT1) was purchased from Dako, Hamburg, Germany. Anti-CD16 (Leullb), anti-CD4 (Leu3-FITC), and anti-CD8 (Leu2-PE) were purchased from Becton-Dickinson, Heidelberg, Germany. Goat anti-mouse phycoerythrin and goat anti-mouse fluorescein was obtained from Southern Biotechnology, AL, USA. Phyto- haemagluttinin was purchased from Biochrom, Berlin, Germany.

\section{ISOLATION OF EFFECTOR CELLS}

Peripheral blood effector cells from normal donors, isolated by a Ficoll density gradient, were depleted of natural killer cells by incubation with anti-CD16 (Leullb) and two subsequent incubations with baby rabbit complement (Cedarlane Ltd, Hornby, Canada) for 60 minutes at $37^{\circ} \mathrm{C}$. Natural killer cell depleted peripheral blood lymphocytes were washed several times before they were used in cytotoxicity assays.

IEL and LPL were obtained by a modified chemical and physical method from that originally described by Bookman and Bull. ${ }^{37}$ Immediately after surgical removal the intestinal specimen was placed in cold Hank's balanced salt solution (Gibco) with $10000 \mathrm{U}$ penicillin/l and 1 g streptomycin/l and transferred to the laboratory. In a laminar flow hood, the intestine was cut longitudinally and washed thoroughly with cold phosphate buffered saline without calcium and magnesium. Then the mucosa was scraped from the underlying muscular layer with a scalpel. The mucosal pieces were incubated for 90 minutes at $37^{\circ} \mathrm{C}$ in Hank's balanced salt solution with $0.7 \mathrm{mM}$ EDTA (Roth KG, Karlsruhe, Germany) and were stirred constantly. The cell suspension was then passed through a stainless steel mesh. The pieces of mucosa were collected from the mesh and washed several times.

IEL were obtained from the cell suspension that was passed through the steel mesh by further filtration through steel meshes with $500 \mu \mathrm{m}$ and $300 \mu \mathrm{m}$ pores. After centrifugation at $400 \mathrm{~g}$ the cells were mixed with RPMI 1640 (Gibco) with 30\% Percoll (Pharmacia LKB, Uppsala, Sweden) and centrifuged at $500 \mathrm{~g}$ for 20 minutes to separate mucus and dead cells. Finally the cells were resuspended in culture medium and layered on a three step density gradient with $65 \%$ and $40 \%$ Percoll and culture medium. Purified IEL could be obtained from the interface between $40 \%$ and $65 \%$ Percoll.

The remaining mucosal pieces without the epithelium were supplemented with $10000 \mathrm{U}$ collagenase CLS 300 (Biochrom), $15000 \mathrm{U}$

TABLE I Phenotypical analysis of several representative intraepithelial and lamina propria lymphocyte population used for 18 hour cytotoxicity studies

\begin{tabular}{|c|c|c|c|}
\hline & $\begin{array}{l}\text { No of } \\
\text { studies }\end{array}$ & $I E L$ & $L P L$ \\
\hline $\begin{array}{l}\text { CD3 positive cells } \\
\text { HML1 positive } \\
\text { cells } \\
\text { CD4/CD8 ratio }\end{array}$ & $\begin{array}{l}7 \\
7 \\
5\end{array}$ & $\begin{array}{l}57 \cdot 5(15 \cdot 6) \% \\
47 \cdot 9(17 \cdot 3) \% \\
(84 \% \text { of } C D 3+) \\
0 \cdot 17\end{array}$ & $\begin{array}{l}64 \cdot 8(17 \cdot 0) \% \\
31 \cdot 9(10 \cdot 1) \% \\
(49 \% \text { of } C D 3+) \\
1 \cdot 25\end{array}$ \\
\hline
\end{tabular}

Freshly isolated intraepithelial (IEL) and lamina propria lymphocytes (LPL) were stained with anti-mouse FITC/antimouse $P E$ as control, anti-CD3-FITC and biotin PE, anti-CD3FITC and HML1-avidin plus biotin-PE, and with CD4-FITC CD8-PE. A total of 10000 cells were run through a Becton Dickinson FACScan flow cytometer and analysed by FACScan software. Cells are gated for the elimination of small volume debris. Markers are used to define positive and negative staining according to controls. Mean (SD) of lymphocytes positive for the indicated antigen is shown. HML $1+/ \mathrm{CD} 3+$ cells are also calculated as percentage of all CD3 + cells. CD4/CD8 ratio is calculated. 
hyaluronidase (Sigma, Deisenhofen, Germany), $0.01 \% \mathrm{wt} / \mathrm{vol}$ DNase (Boehringer, Mannheim, Germany), and $0.01 \% \mathrm{wt} / \mathrm{vol}$ trypsin inhibitor (Sigma) in $100 \mathrm{ml}$ of culture medium and kept in the refrigerator overnight. The next morning the mucosal pieces were incubated for 90 minutes at $37^{\circ} \mathrm{C}$ under constant stirring. After enzymatic digestion, the cell suspension was again filtered through several steel meshes. The Percoll gradients for LPL were done in the same way as that described for IEL.

\section{IMMUNOFLUORESCENCE STAINING AND FLOW CYTOMETRY}

Immunofluorescent stains were done as previously described." Analysis was undertaken with a FACScan flow cytometer using software programs supplied by Becton Dickinson.

\section{CYTOTOXICITY ASSAY}

Cytotoxicity assays were undertaken as previously described..$^{25}$ Briefly, 5000 K562 cells labelled with ${ }^{51} \mathrm{Cr}$ were added to effector cells, whose number was calculated for the indicated effector/target cell ratio (E/T ratio) in a total volume of $200 \mu \mathrm{l}$. For induced cytotoxicity phytohaemagluttinin (1:100 dilution), anti-CD3 $(1: 100)$, and the mixture of anti-CD2 antibodies (all 1:4000) were added. The assay was harvested after the indicated time with a Skatron harvesting press and the released radioactivity was counted in the supernatant by a gamma radiation counter. Spontaneous release of ${ }^{5} \mathrm{Cr}$ from $\mathrm{K} 562$ was less than $6 \%$ in six hour and less than $18 \%$ in 18 hour assays. Total release was induced by detergent lysis with $1 \%$ Triton $\mathrm{X} 100$. The percentage of cytotoxicity was estimated from the released radioactivity by the following formula using mean counts per minute from three (test) or six (spontaneous and total) wells:

$\%$ specific ${ }^{\text {s' }} \mathrm{Cr}$ release $=\frac{\text { test release }- \text { spontaneous release }}{\text { total release }- \text { spontaneous release }} \times 100$

Finally, for phytohaemagluttinin, CD3, and $\mathrm{CD} 2$ induced cytotoxicity, the spontaneous cytotoxicity of the same cell population and the same $\mathrm{E} / \mathrm{T}$ ratio was subtracted. The calculated toxicity showed only minimal variation for repeat measurements (intra-assay variation of the mean

TABLE II Mean specific cytotoxicity and the number of subjects with more than 5\% specific lysis at a 50:1 ratio of effector/target cells for intraepithelial and laminal propria lymphocytes after six hours' incubation

\begin{tabular}{|c|c|c|c|c|}
\hline & \multicolumn{2}{|c|}{ Intraepithelial lymphocytes } & \multicolumn{2}{|c|}{ Lamina propria lymphocytes } \\
\hline & $\begin{array}{l}\% \text { Specific } \\
\text { cytotoxicity }\end{array}$ & $\begin{array}{l}\text { No of individuals } \\
\text { with }>5 \% \text { lysis }\end{array}$ & $\begin{array}{l}\% \text { Specific } \\
\text { cytotoxicity }\end{array}$ & $\begin{array}{l}\text { No of individuals } \\
\text { with }>5 \% \text { lysis }\end{array}$ \\
\hline $\begin{array}{l}\text { SCMC } \\
\text { PHA-ICC } \\
\text { Anti-CD3-ICC }\end{array}$ & $\begin{array}{l}0 \cdot 8 \\
2 \cdot 8 \\
1 \cdot 1\end{array}$ & $\begin{array}{l}0 / 10 \\
3 / 10 \\
1 / 7\end{array}$ & $\begin{array}{r}2 \cdot 6 \\
9 \cdot 5 \\
10 \cdot 4\end{array}$ & $\begin{array}{l}3 / 11 \\
8 / 11 \\
8 / 11\end{array}$ \\
\hline
\end{tabular}

Isolated intraepithelial lymphocytes and lamina propria lymphocytes were used as effector cells for cytotoxicity against " $\mathrm{Cr}$ radiolabelled K562 cells. Effector/target ratios of $100: 1$ were done, if sufficient cells were available. E/T ratios of $50: 1,25: 1$, and 12:5:1 were determined in all individuals (data for $50: 1$ ratio are shown). 5000 target cells were cocultured with effector cells and the indicated trigger substance at $37^{\circ} \mathrm{C}$ in an incubator. After six hours the supernatants were cytotoxicity see methods). Spontaneous cell mediated cytotoxicity (SCMC), phytohaemagluttinin (PHA) and anti-CD3 induced cell mediated cytotoxicity (anti-CD3-ICC) were determined in parallel. $\pm 15 \%)$ and even at low toxicity values we could show $\mathrm{E} / \mathrm{T}$ ratio dependent changes of toxicity (four different ratios). In our experiments, at least $5 \%$ specific lysis at a $50: 1 \mathrm{E} / \mathrm{T}$ ratio was necessary to observe a consistent decline at lower ratios.

\section{STATISTICS}

Phenotyping and cytotoxicity results are shown as mean (SEM). Group comparisons were calculated by Wilcoxon U test. Significance for a group difference was reached at a probability $\mathrm{p}<0.05$.

\section{Results}

PHENOTYPES OF IEL AND LPL

From tissue specimen ranging from 10 to $40 \mathrm{~cm}$ we were able to isolate 4 to 25 million IEL and 11 to 160 million LPL. IEL yields per area are much higher in the ileum and right sided colon than in the sigmoid and rectum. IEL and LPL cell yields per area were generally increased in inflamed mucosa. The phenotypical analysis of several representative IEL and LPL populations used for 18 hour cytotoxicity studies are shown in Table I.

\section{CONTROLS FOR CYTOTOXICITY}

In preliminary experiments, we determined antibody concentrations for the saturation of the receptor binding sites on 500000 effector cells in $200 \mu \mathrm{l}$ by phenotypical analysis. Indirect staining with OKT3 mab was saturated at 1:4000, anti-CD2 (mixture) staining at a 1:20000 dilution. Maximum cytotoxicity of peripheral blood lymphocytes and LPL was induced by an antibody concentration at or above the saturating concentration (data not shown). Therefore in further experiments only antibody concentrations that exceeded the saturating dose by four to five times were used. Antibodies or phytohaemagluttinin alone did not induce cytotoxicity against target cells (data not shown).

\section{CYTOTOXIC FUNCTION IN SIX HOUR ASSAYS}

In order to evaluate the cytotoxic function of IEL and LPL we tested peripheral blood lymphocytes depleted of CD16+ cells for spontaneous cell mediated cytotoxicity and $\mathrm{CD} 3$ induced cell mediated cytotoxicity. As expected the spontaneous cell mediated cytotoxicity activity of peripheral blood lymphocytes without CD16+ cells was below 3\% specific lysis in all experiments. The CD3 induced cell mediated cytotoxicity of these cells was $11 \cdot 4(4 \cdot 7) \%$ at an E/T ratio of 100:1 and fell with lower ratios $(n=6$, data not shown). Incubation of peripheral blood lymphocytes with EDTA or EDTA and enzymes similar to IEL or LPL did not change the cytotoxicity significantly. In three of four peripheral blood lymphocyte preparations, cytotoxicity was slightly raised by enzyme treatment (data not shown).

When isolated LPL and IEL were incubated for six hours with K 562 cells and various stimuli, 


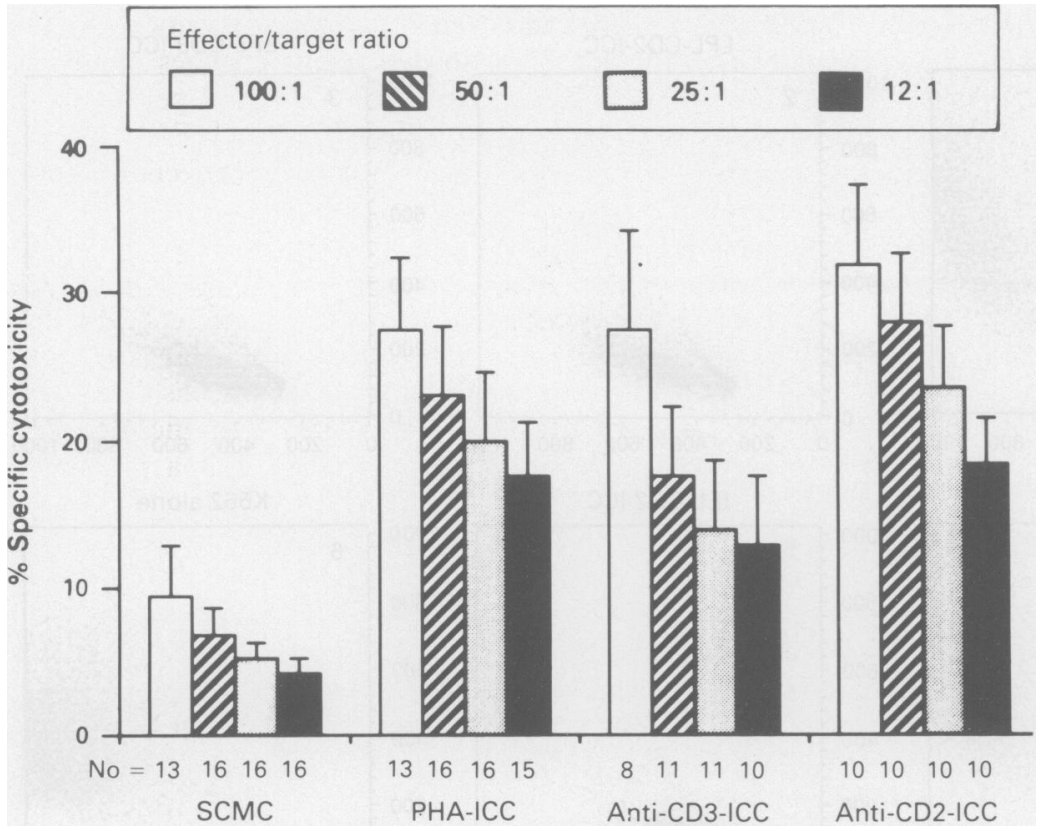

Figure 1: Cytotoxicity of lamina propria lymphocytes measured as the percentage of ${ }^{\text {s1 }} \mathrm{Cr}$ release from labelled K562 cells after incubation with different stimuli for 18 hours. Mean (SEM) cytotoxicity is shown for four effector target cell ratios. Spontaneous cell mediated cytotoxicity (SCMC) is already subtracted from phytohaemagluttinin (PHA), anti-CD3, and anti-CD2 antibody induced cell mediated lysis.

we rarely found a spontaneous cell mediated cytotoxicity of LPL above $5 \%$ specific lysis (3 of 11 specimens tested, Table II). The mean spontaneous cell mediated cytotoxicity of LPL at a $50: 1$ effector target cell ratio was $2 \cdot 6 \%$ (range $0-8 \cdot 5 \%$ ), yet an $\mathrm{E} / \mathrm{T}$ ratio dependent decline could be found in the individuals with ${ }^{51} \mathrm{Cr}$ releases above $5 \%$ (data not shown). IEL had no spontaneous cell mediated cytotoxicity.

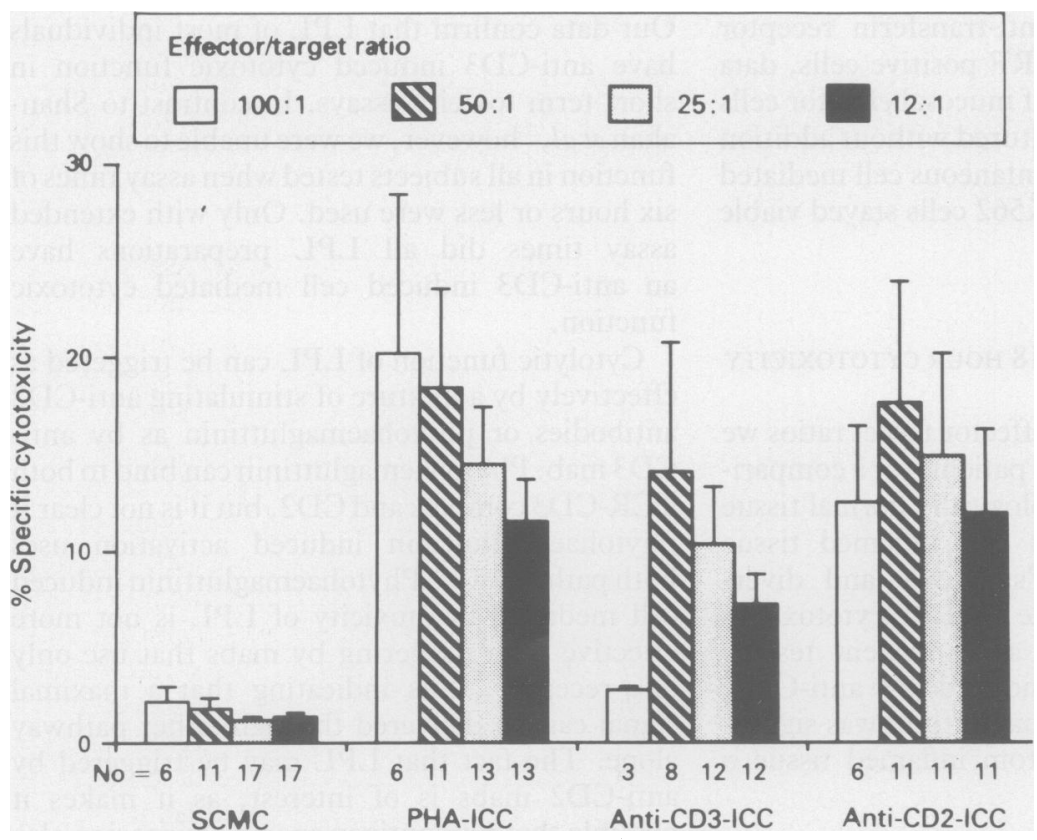

Figure 2: Cytotoxicity of intraepithelial lymphocytes measured as the percentage ${ }^{\mathrm{C}} \mathrm{Cr}$ release from labelled K562 cells after incubation with different stimuli for 18 hours. Mean (SEM) cytotoxicity is shown for four effector target cell ratios. Spontaneous cell mediated cytotoxicity $(S C M C)$ is already subtracted from phytohaemagluttinin $(P H A)$, anti-CD3, and anti-CD2 antibody induced cell mediated lysis.
Anti-CD3 and phytohaemagluttinin induced cell mediated cytotoxicity of IEL and LPL after six hours' incubation are shown in Table II. One patient with Crohn's disease and one with ulcerative colitis were examined in this assay. Preliminary data from these few experiments found no significant differences between patients with inflammatory or neoplastic colonic disease. There was also no difference between inflamed and uninflamed tissue (normal tissue from carcinoma $v$ inflamed tissue from diverticulitis and inflammatory bowel disease).

\section{CYTOTOXICITY IN 18 HOUR ASSAYS}

After 18 hours' incubation in a CD3 induced cell mediated cytotoxicity assay, we found a $21 \cdot 5 \%$ mean specific lysis of K562 by CD16 depleted peripheral blood lymphocytes $(n=6$, data not shown). The CD3 induced cell mediated cytotoxicity of peripheral blood lymphocytes was $\mathrm{E} / \mathrm{T}$ ratio dependent and fell to $10.9 \%$ at a ratio of $12 \cdot 5: 1$.

The mean spontaneous cell mediated cytotoxicity of IEL after 18 hours' incubation (Fig 2) was still below 5\%. LPL showed a low yet definite mean spontaneous cell mediated cytotoxicity after 18 hours (Fig 1). The addition of phytohaemagluttinin, anti-CD3, and a mixture of stimulating anti-CD2 antibodies to effector and target cells induced a clear lytic function of both LPL and IEL (Figs 1 and 2). In two experiments, $\mathrm{T} 84$ colon cancer cells were used as target cells in parallel to K562 cells. Spontaneous cytotoxicity against T84 cells by IEL and LPL was below $5 \%$ specific lysis - similar to $\mathrm{K} 562$ cell lysis. Induced cytotoxicity (anti-CD3, anti-CD2, and phytohaemagluttinin) against T84 cells was present in both experiments and showed an effector target cell ratio dependency (data not shown).

\section{CYTOPATHOLOGICAL EFFECT ON K562 CELLS} AFTER 8 TO 10 DAYS

The function of IEL and LPL was further investigated after longer time intervals. In three experiments cell mixtures with and without antibodies or phytohaemagluttinin were set up in the same way as those in the cytotoxicity assays and cultured for eight to 10 days. K562 cells were used unattenuated and unlabelled. In the pres-

TABLE III Cytotoxicity of intraepithelial lymphocytes (IEL) and lamina propria lymphocytes $(L P L)$ according to disease groups

\begin{tabular}{|c|c|c|}
\hline & $\begin{array}{l}\text { Normal tissue from } \\
\text { carcinoma subjects }\end{array}$ & $\begin{array}{l}\text { Inflamed tissue from } \\
\text { diverticulitis and } \\
\text { Crohn's disease }\end{array}$ \\
\hline \multicolumn{3}{|l|}{ IEL: } \\
\hline SCMC & $1 \cdot 1(0 \cdot 5)(n=5)$ & $0.9(0 \cdot 5)(n=5)$ \\
\hline PHA-ICC & $24.6(6.6)(\mathrm{n}=5)^{\star}$ & $5.5(2.0)(\mathrm{n}=5)^{\star}$ \\
\hline CD3-ICC & $17 \cdot 9(1 \cdot 2)(\mathrm{n}=3)^{\star}$ & $2.8(0.9)(n=4)^{\star}$ \\
\hline CD2-ICC & $18.6(6.1)(n=5) \star$ & $6 \cdot 2(2 \cdot 8)(\mathrm{n}=5)^{\star}$ \\
\hline \multicolumn{3}{|l|}{ LPL: } \\
\hline SCMC & $5 \cdot 8(2 \cdot 6)(n=9)$ & $8 \cdot 4(3 \cdot 1)(n=6)$ \\
\hline PHA-ICC & $22 \cdot 7(6.9)(n=9)$ & $21 \cdot 5(8 \cdot 7)(n=6)$ \\
\hline CD3-ICC & $13 \cdot 2(2 \cdot 7)(n=5)$ & $21 \cdot 1(10 \cdot 7)(n=5)$ \\
\hline CD2-ICC & $23 \cdot 5(3 \cdot 4)(n=5)$ & $29 \cdot 4(10 \cdot 3)(n=4)$ \\
\hline
\end{tabular}

Mean (SEM) cytotoxicity of the indicated number of independent experiments. 18 hour assay at $50: 1$ effector/target ratio. ^Indicates significant differences between normal and inflamed tissue calculated by Wilcoxon $U$ test. 

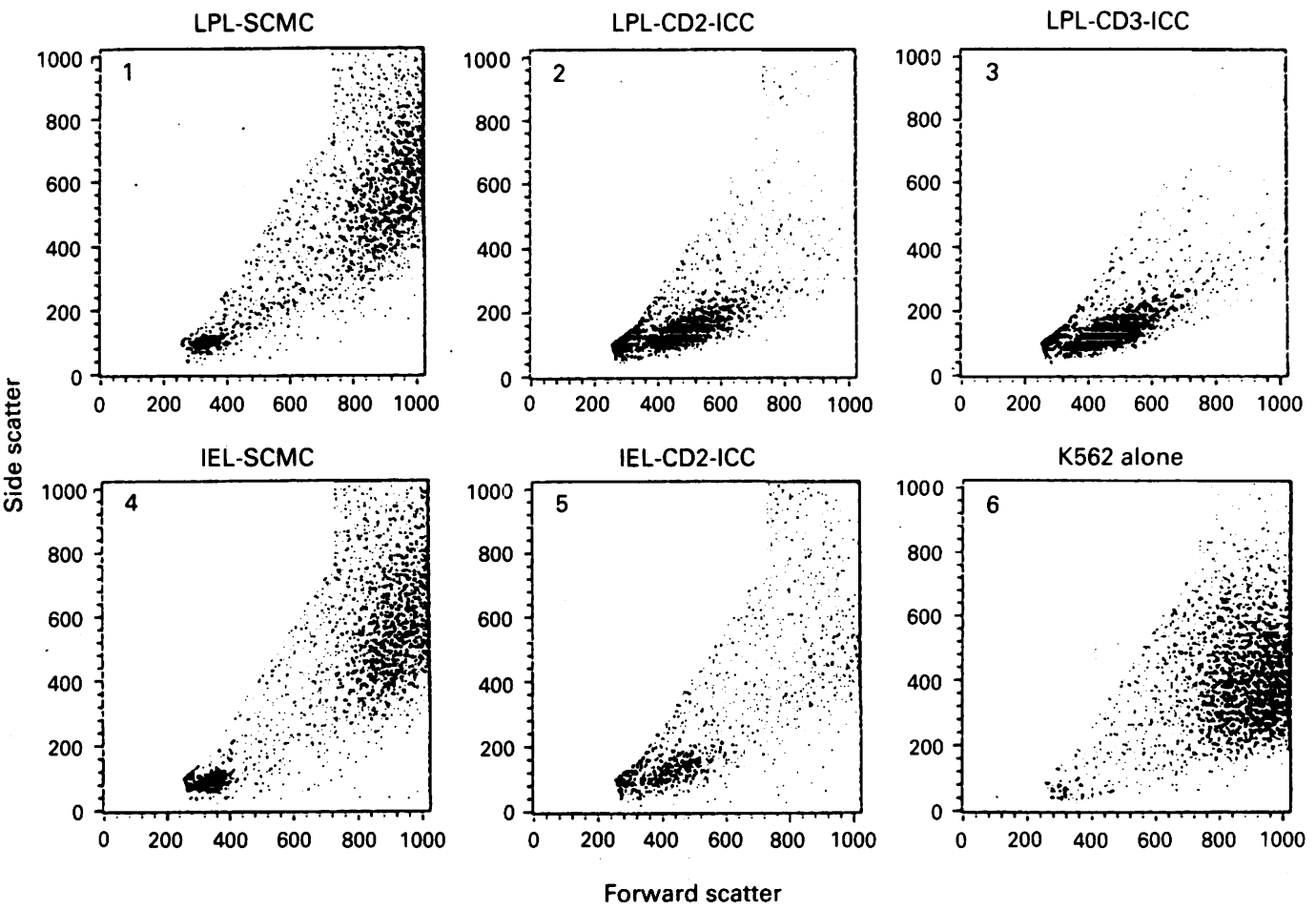

Figure 3: Flow cytometric analysis of cells cultured for 8 to 10 days. Forward scatter (size of the particles) is shown on the horizontal axis and side scatter (granularity of the particles) on the vertical axis. Panels 1-3 contained 500000 lamina propria lymphocytes (LPL) and 5000 K562 at day 0. Panels 4 and 5 contained intraepithelial lymphocytes (IEL) and K562 cells (also ratio 100:1) and panel 6 contained only K562 cells. No trigger substance was added in panels 1 and 4, anti-CD2 mabs were added in panels 2 and 5 , and anti-CD 3 mab was added in panel 3 . The gate was set to eliminate debris that accumulated during culture. More than $98 \%$ of mucosal $T$ cells identified by anti-CD3 were found in the population with low forward and side scatter (fluorescence staining not shown). K562 cells are considerably bigger cells with wider variation of both parameters shown. The K562 cell population is easily identified in panels 1, 4, and 6. In panels 2, 3, and 5 K562 cells did not expand. $S C M C=$ spontaneous cell mediated cytotoxicity; ICC = induced cell mediated cytotoxicity.

ence of phytohaemagluttinin, anti-CD3, or antiCD2, IEL and LPL were able to prevent the expansion of K562 cells (example shown in Fig 3). Similar results were found at 100:1 and 10:1 E/T ratios. K562 cells could not be detected by double staining with anti-CD3 and anti-HLADR or anti-CD3 and anti-transferin receptor (CD3 negative, DR or TRF positive cells, data not shown). In contrast, if mucosal effector cells and K562 cells were cocultured without addition of trigger substances (spontaneous cell mediated cytotoxicity assay) then K562 cells stayed viable and proliferated (Fig 3).

INFLAMMATION RELATED 18 HOUR CYTOTOXICITY OF IEL AND LPL

At 50:1, 25:1, and 12:1 effector target ratios we were able to assess enough patients for a comparison between histomorphologically normal tissue from carcinoma patients and inflamed tissue from those with Crohn's disease and diverticulitis. As shown in Table III, LPL cytotoxicity is not different in any assay system tested. However, cytotoxicity induced by anti-CD2, anti-CD3, and phytohaemagluttinin was significantly reduced in IEL from inflamed tissue $v$ normal tissue.

\section{Discussion}

These experiments show that human IEL and LPL have toxic activity after triggering through $\mathrm{CD} 2$ and $\mathrm{CD} 3$. The induced toxicity of LPL is the same in normal and inflamed mucosa, but IEL toxicity is significantly reduced in inflamed mucosa.

\section{TOXICITY OF LPL}

Our data confirm that LPL of most individuals have anti-CD3 induced cytotoxic function in short term toxicity assays. In contrast to Shanahan et $a l,{ }^{27}$ however, we were unable to show this function in all subjects tested when assay times of six hours or less were used. Only with extended assay times did all LPL preparations have an anti-CD3 induced cell mediated cytotoxic function.

Cytolytic function of LPL can be triggered as effectively by a mixture of stimulating anti-CD2 antibodies or phytohaemagluttinin as by antiCD3 mab. Phytohaemagluttinin can bind to both TCR-CD3 complex and CD2, but it is not clear if phytohaemagluttinin induced activation uses both pathways. ${ }^{33-36}$ Phytohaemagluttinin induced cell mediated cytotoxicity of LPL is not more effective than triggering by mabs that use only one receptor, thus indicating that a maximal signal can be delivered through either pathway alone. The fact that LPL may be triggered by anti-CD2 mabs is of interest, as it makes it possible that non-antigen specific triggering also contributes to cytotoxicity in vivo.

In contrast to other investigators, ${ }^{615}$ we found a modest but unequivocal mean spontaneous cell mediated cytotoxicity of LPL at usual $\mathrm{E} / \mathrm{T}$ ratios against K562 cells after 18 hours. Using ex- 
tremely high E/T ratios, Gibson $e t a l^{38}$ and Van Tolet $a l^{39}$ were also able to show the spontaneous cell mediated cytotoxicity of LPL. But in spite of this low yet detectable spontaneous cell mediated cytotoxicity, K562 cells alone are not sufficient to stimulate effective spontaneous toxicity of LPL after several days. In experiments lasting 8-10 days we showed that only those cultures that included triggering mediators showed activation (increase in size) of LPL together with efficient elimination of K562 cells (Fig 3).

\section{PURITY OF IEL}

Most published studies have used small bowel tissue for cell isolation as colonic mucosa contains considerably lower numbers of IEL. ${ }^{340} 41$ Histological examination of small and large bowel showed that most IEL $T$ cells are HML-1 positive. ${ }^{42}$ In agreement with these data, ileal and colonic IEL showed only small numbers of HML1 negative T cells. If HML1 staining was calculated as a fraction of CD8 positive cells, virtually all cells were positive. The CD4/CD8 ratios of isolated IEL and LPL populations in the present experiments are in the same range as those reported by other investigators. These data show that our isolation procedure leads to populations that are at least enriched for cells from the appropriate compartments.

\section{CYTOTOXICITY OF IEL}

Our experiments confirm previous data which show that IEL do not exert spontaneous cytotoxicity against K562 cells. Colonic and ileal IEL are also not cytotoxic to T84 colon tumour cells. Interestingly, data by Taūnk et $a l^{20}$ show a spontaneous cell mediated cytotoxicity of jejunal IEL against DLD1 and HT29 colonic tumour cells. The source of the IEL (jejunal, ileal, or colonic) or the target specificity (T84 colon tumour $v$ other epithelial tumour cells) may explain these differences.

Chiba $e t a l$ were the first to use phytohaemagluttinin to induce cytotoxicity of IEL preparations. This study suggests that freshly isolated IEL have a cytotoxic function but effector cells were not phenotyped and the study does not provide data proving the origin of the isolated cells. We show that freshly isolated IEL have CD3, CD2, or phytohaemagluttinin induced cytotoxicity in 18 hour assays. Parallel determinations show that IEL cytotoxicity is not significantly different from LPL toxicity in normal mucosa. As the phenotypes of IEL and LPL are clearly distinguished we conclude that 'true' IEL can mediate this function. We suggest that the documented cytotoxicity is mediated by $T$ cells, as CD3, CD2, and phytohaemagluttinin are similarly effective. The time course of the toxic activity of IEL seems to be longer than that of LPL and peripheral blood lymphocytes, as only the 18 hour assays allow the evaluation of this cell population. The slow reaction of IEL after triggering could be the result of impairment by the isolation procedure, but peripheral blood lymphocytes treated in the same way do not show delayed toxic function. Another reason may be the mechanism of cytotoxicity. The mechanism of lysis of target cells through cytolytic cells is not known exactly and might well be diverse for different effector cells (perforins, production of adenosine triphosphate and other cytotoxic substances like tumour necrosis factors or interferon gamma. ${ }^{444}$ The time kinetics of the various toxic mechanisms are probably distinct.

DISEASE DEPENDENT CHANGES IN CYTOTOXICITY In preliminary data we showed a significant reduction in induced cytolytic activity of IEL isolated from patients with inflamed mucosa compared with normal mucosa from carcinoma patients. Patients with Crohn's disease and diverticulitis both have low IEL cytotoxicity induced by anti-CD3, anti-CD2, and phytohaemagluttinin. Several possible explanations for these results need to be examined: Firstly, IEL toxicity could be reduced in vivo as well. Secondly, IEL could react suboptimally or be unresponsive to in vitro stimulation because they have been stimulated shortly before. Thirdly, our IEL population could contain target cells that compete with K562 or T84 cells, thus resembling a cold target inhibition assay. Further investigations are needed to explore these possibilities.

The cytotoxic function of IEL and LPL after triggering through $\mathrm{CD} 2$ and $\mathrm{CD} 3$ extends the number of possible effector mechanisms in the human mucosal immune system. Monoclonal antibodies against $\mathrm{CD} 2$ and $\mathrm{CD} 3$ are clearly not physiological trigger substances, but obviously antigens, superantigens, or heat shock proteins of environmental (nutritional, bacterial or viral) or endogenous origin could also trigger the CD3TCR complex. LFA3 is a known physiological ligand for CD2 that does not stimulate these cells - similar to anti-T11-, antibody. As triggering by monoclonal antibodies reacting with other epitopes of CD2 is possible, however, there may be physiological ligands with similar activity. These toxic functions of colonic IEL and LPL need to be explored further as immunological reactions such as anti-tumour activity or epithelial cell destruction in inflammatory conditions could be explained through this mechanism.

This work was supported by grants Ru 364/2-1 and 2-2 from Deutsche Forschungsgemeinschaft. Anti-CD2 monoclonal antibodies clone 3T48B5, anti-T11.2, and anti-T11.3 were kindly provided by $S$ Meuer, Deutsches Krebsforschungszentrum Heidelberg, Germany. Surgical specimen were provided by $H$ P Wasmer, B Lühnstedt, and R Engemann, Department of Surgery, University of Würzburg and H Schmitt, Juliusspital, Würzburg.

1 Brandtzaeg P, Halstensen TS, Kett K, Krajci P, Kvale D, Rognum TO, et al. Immunobiology and immunopathology of human gut mucosa: humoral immunity and intraepithelial lymphocytes. Gastroenterology 1989; 97 : 1562-84.

2 Targan SR. Immunologic mechanisms in intestinal disease. Ann Intern Med 1987; 106: 853-70.

3 Ebert EC, Roberts AI, Brolin RE, Raska K. Examination of the low proliferative capacity of human jejunal intrathe low proliferative capacity of human jejunal intra-

4 Ebert EC. Proliferative response of human intraepithelial Ebert EC. Proliferative response of human intraepithelial
lymphocytes to various T cell stimuli. Gastroenterology 1989; lymphocytes to

5 MacDermott RP, Franklin GO, Jenkins KM, Kodner IJ Nash GS, Weintrieb IJ. Human intestinal mononuclea cells. I. Investigation of antibody-dependent, lectin-induced and spontaneous cell-mediated cytotoxic capabilities. Gastroenterology 1980; 78: 47-56.

6 Falchuk ZM, Barnhard E, Machado I. Human colonic mononuclear cells: studies of cytotoxic function. Gut 1981;22: $290-4$.

7 Chiba M, Bartnik W, ReMine SG, Thayer WR, Shorter RG Human colonic IEL and LPL: cytotoxicity in vitro and potential side effects of the isolation method on functional properties. Gut 1981; 22: 177-86. 
8 Gibson PR, Dow EL, Selby WS, Strickland RG, Jewell DP. Natural killer cells and spontaneous cell mediated cytotoxicity in the human intestine. Clin Exp Immunol 1984; 56 : 438-44.

9 Shorter RG, McGill DB, Bahn RC. Cytotoxicity of mononuclear cells for autologous colonic epithelial cells in colonic disease. Gastroenterology 1984; 86: 13-22.

10 Auer IO, Röder A, Reinecke C, Grudzinsky K, Rüthlein J. Studies on intestinal natural killer (NK) cell activity (spontaneous mediated cytotoxicity; SCMC) and its immunoregulatory control in patients with chronic inflammatory bowel disease (IBD) and controls. Gastroenterology 1985; 76: bowel 1311 .

11 Auer IO, Rüthlein J, Röder A, Reinecke C, Grudzinsky K. Untersuchungen der intestinalen spontanen zellvermittelten Zytotoxizität und ihrer Immunoregulation bei Patienten mit chronisch-entzündlichen Darmerkrankungen und Kontrollen. Immun Infekt 1986; 14: 22-3.

12 Cerf-Bensussan N, Guy-Grand D, Griscelli C. Intraepithelial lymphocytes of the human gut: Isolation, characterisation and study of natural killer activity. Gut 1985; 26: 81-8.

13 Hogan PG, Hapel AJ, Doe WF. Lymphokine-activated and natural killer cell activity in human intestinal mucosa. I Immunol 1985; 135: 1731-8.

14 Shanahan F, Brogan M, Targan S. Human mucosal cytotoxic effector cells. Gastroenterology 1987; 92: 1951-7.

15 Fiocchi C, Tubbs RR, Yougman KR. Human intestinal mucosal mononuclear cells exhibit lymphokine-activated killer cell activity. Gastroenterology 1985; 88: 625-37.

16 MacDermott RP, Bragdon MJ, Kodner IJ, Bertovich MJ Deficient cell mediated cytotoxicity and hyporesponsiveness to interferon and mitogenic lectin activation by inflammatory bowel disease peripheral blood and intestinal mononuclear cells. Gastroenterology 1986; 90: 6-11.

17 Roche JK, Fiocchi C, Yougman KR. Sensitisation to epithelia antigens in chronic mucosal inflammatory bowel disease: characterisation of human intestinal mucosa-derived mononuclear cells reactive with purified epithelial cell-associated components in vitro. $\mathcal{J}$ Clin Invest $1985 ; 75: 522-30$.

18 Tagliabue A, Befus AD, Clark DA, Bienenstock J, Characteristics of natural killer cells in the murine intestina teristics of natural killer cells in the murine intestinal epithelium

19 Arnaud-Battandier F, Bundy BM, O'Neil M, Bienenstock J Nelson DL. Cytotoxic activities of gut mucosal lymphoid cells in guinea pigs. F Immunol 1978; 121: 1059-65.

20 Taūnk J, Roberts AI, Ebert EC. Spontaneous cytotoxicity of human intraepithelial lymphocytes against epithelial cel tumors. Gastroenterology 1992; 102: 69-75.

21 Mentzer SJ, Barbosa JA, Burakoff SJ. T3 monoclonal antibody activation of nonspecific cytolysis: A mechanism of CTL inhibition. F Immunol 1985; 135: 34-8.

22 Schrezenmeier H, Kurrle R, Wagner H, Fleischer B. Activation of human T lymphocytes: III. Triggering of bystander cytotoxicity in cytotoxic T cell clones by antibodies against T3 antigen or by a calcium ionophore. Eur $\mathcal{f}$ Immunol 1985 ; 15: 1019-24.

23 Van Seventer G, Kuijpers KC, Van Lier RAW, De Groot ER Aarden LA, Melief CJM. Mechanism of inhibition and induction of cytolytic activity in cytotoxic T lymphocytes by CD3 monoclonal antibodies. F Immunol 1987; 139: 2545-50.

24 Phillips JH, Lanier LL. Lectin-dependent and anti-CD induced cytotoxicity are preferentially mediated by peripheral blood cytotoxic $\mathrm{T}$ lymphocytes expressing Leu7 antigen. $\mathcal{F}$ Immunol 1986; 136: 1579-85.

25 Rüthlein J, James SP, Strober W. Role of CD2 in activation and cytotoxic function in $\mathrm{CD} 8 / \mathrm{Leu}-7$ positive $\mathrm{T}$ cells. f Immunol 1988; 141: 3791-7.
26 Shanahan F, Leman B, Deem R, Niederlehner A, Brogan M, Targan S. Enhanced peripheral blood $\mathrm{T}$ cell cytotoxicity in inflammatory bowel disease. F Clin Immunol 1989; 9: 55-64. 27 Shanahan F, Deem R, Nayersina R, Leman B, Targan S Human mucosal T-Cell cytotoxicity. Gastroenterology 1988 94: $960-7$

28 Rüthlein J, Heinze G. Anti-CD3 or PHA-induced cytotoxicity in human intraepithelial and lamina propria lymphocytes. Immunol Res 1991; 10: 226-9.

29 Meuer SC, Hussey RE, Fabbi M, Fox D, Acuto O, Fitzgerald $\mathrm{KA}$, et al. An alternative pathway of $\mathrm{T}$ cell activation: A functional role for the $50 \mathrm{kD}$ T11 sheep erythrocyte receptor protein. Cell 1984; 36: 897-906.

30 Pirzer UC, Schuermann G, Post S, Betzler M, Meuer SC. Differential responsiveness to $\mathrm{CD} 3-\mathrm{Ti}$ vs. $\mathrm{CD} 2$-dependen activation of human intestinal $\mathrm{T}$ lymphocytes. Eur $\mathcal{f}$ Immunol 1990; 20: 2339-42.

31 Qiao L, Schürmann G, Betzler M, Meuer SC. Activation and signalling status of human lamina propria $\mathrm{T}$ lymphocytes. Gastroenterology 1991; 101: 1529-36.

32 Siliciano RF, Pratt JC, Schmidt RE, Ritz J, Reinherz EL. Activation of cytolytic $T$ lymphocyte and natural killer function through the T11 sheep erythrocyte binding protein. Nature 1985; 317: 428-30.

33 Leca G, Boumsell L, Fabbi M, Reinherz EL, Kanellopoulos $J M$. The sheep erythrocyte receptor and both alpha and beta chains of the human $T$-lymphocyte antigen receptor bind the chains of the human T-lymphocyte antigen receptor bind the
mitogenic lectin (phytohaemagglutinin)-from Phaseolus vulmitogenic lectin (phytohaemagglutinin)-from
garis. Scand f Immunol 1986; 23: 535-44.

garis. Scand F Immunol 1986; 23: 535-44.
34 O'Flynn K, Krensky AM, Beverly PC, Burakoff SJ, Linch DC. Phytohaemagglutinin activation of T cells through the sheep red blood cell receptor. Nature 1985; 313: 686-7.

35 O'Flynn K, Knott LJ, Russul-Saib M, Abdul-Gaffar R, Morgan G, Beverley PC, et al. CD2 and $\mathrm{CD} 3$ antigen mobilize Ca2+ independently. Eur F Immunol 1986; 16 $580-4$.

36 Kanellopoulos JM, DePetris S, Leca G, Crumpton MJ. The mitogenic lectin from Phaseolus vulgaris does not recognize the T3 antigen of human $\mathrm{T}$ lymphocytes. Eur 7 Immunol $1985 ; 15: 479-86$.

37 Bookman MA, Bull DM. Characteristics of isolated intestinal mucosal lymphoid cells in IBD. Gastroenterology 1979; 77 503-10

38 Gibson PR, Dow EL, Selby WS, Strickland RG, Jewell DP. Natural killer cells and spontaneous cell mediated cytotoxicity in the human intestine. Clin Exp Immunol 1984; 56 438-44.

39 Van Tol EA, Verspaget HW, Peña AS, Kraemer CV, Lamers CB. The CD56 adhesion molecule is the major determinan for detecting non-major-histocompatibility complex restricted cytotoxic mononuclear cells from intestinal lamin propria. Eur F Immunol 1992; 22: 23-9.

40 Mowat A McI. Human intraepithelial lymphocytes. Springer Semin Immunopathol 1990; 12: 165-90.

41 Herberman RB, Hiserodt J, Vujonovic N, Balch C Lotzova $E$ Bolhuis R, et al. Lymphokine-activated killer cell activity: Characteristics of effector cells and their progenitors in blood and spleen. Immunol Today 1987; 8: 178-81.

42 Cerf-Bensussan N, Jarry A, Brousse N, Lisowska-Grospierre B, Guy-Grand D, Griscelli C. A monoclonal antibody (HML-1) defining a novel membrane molecule present on human intestinal lymphocytes. Eur F Immunol 1987; 17 1279-85.

43 Di Virgilio F, Pizzo P, Zanovello P, Bronte V, Collavo D. Extracellular ATP as a possible mediator of cell mediated cytotoxicity. Immunol Today 1990; 11: 274-7.

44 Young JD-E. Killing of target cells by lymphocytes: A mechanistic view. Physiol Rev 1989; 69: 250-314. 